\title{
Review on the Estimating the Effective Way for Managing the Produced Water: Case Study
}

\author{
Mohamed A. Kassab ${ }^{1 *}$, Ali E. Abbas ${ }^{2}$, Iman Elgamal ${ }^{3}$, Basem M. Shawky³, \\ Mahmoud F. Mubarak ${ }^{*}$, R. Hosny ${ }^{1}$ \\ ${ }^{1}$ Egyptian Petroleum Research Institute (EPRI), Cairo, Egypt \\ ${ }^{2}$ Faculty of Petroleum and Mining Engineering-Suez University, Suez, Egypt \\ ${ }^{3}$ Bader EL-Din Petroleum Company (BAPETCO), Cairo, Egypt \\ Email: ^mkassab68@yahoo.com, *fathy8753@yahoo.com
}

How to cite this paper: Kassab, M.A., Abbas, A.E., Elgamal, I., Shawky, B.M., Mubarak, M.F. and Hosny, R. (2021) Review on the Estimating the Effective Way for Managing the Produced Water: Case Study. Open Journal of Modern Hydrology, 11, 19-37.

https://doi.org/10.4236/ojmh.2021.112002

Received: April 4, 2021

Accepted: April 27, 2021

Published: April 30, 2021

Copyright (C) 2021 by author(s) and Scientific Research Publishing Inc. This work is licensed under the Creative Commons Attribution International License (CC BY 4.0).

http://creativecommons.org/licenses/by/4.0/

\begin{abstract}
Water manufactured is the primary waste source in the oil and gas industry. Because of the rising amount of waste worldwide, the environmental effect of wastewater has become a primary environmental concern in recent years. The vast amounts involved have resulted in considerable costs to the industry for handling produced water. This research explains the wide variety of choices for water management. This research's first phase was water minimization techniques, consisting of three different applications made in three different wells (Well 1, Well 2 and Well 3 ) and water recycling and reuse by two techniques. In Well 1, Mechanical shut-off technique was applied using through tubing bridge plug and $5 \mathrm{~m}$ cement dumped above it to isolate the watered out zone; as per water oil ration plot the water cut is decreased from $100 \%$ to $4 \%$ and the production is increased from 0 to $400 \mathrm{bcpd}$. In Well 2, Chemical shut-off technique using a polymer called Brightwater has been used to block channeling through high permeability intervals after PLT log detected it, and the result was brilliant, the water cut decreased from $60 \%$ to $25 \%$, also the oil production increase from 500 to 3000 bopd. In Well 3, downhole separator installed in it using workover (unfortunately, this technique is not applied in middle east till the moment so this application is taken from an oil field in Canada)and the result was perfect, the water cut decreased from $70 \%$ to $28 \%$, also the oil production increase from 44 to 100 bopd. This study tried to clarify and compare the most widely used water management techniques using one of the Western Desert (W.D.) (enhanced for oil recovery, constructed wetland).
\end{abstract}

\section{Keywords}

Produced Water, Water Production Problem, Management Techniques, 
Water Minimization Techniques, Recycling and Reusing Technologies

\section{Introduction}

Worldwide, the oil and gas industry generates more than 70 billion barrels of produced water per year. Within the United States (U.S.) alone, between 15 and 20 billion barrels of produced water are generated each year. Management of these large quantities of water can be costly, and can determine whether wells are profitable or not. Companies must consider many different options for managing produced water. The technologies and strategies used in the manipulation of produced water are described in three steps-minimization, recycling/reuse and disposal-water management or pollution management hierarchy. Produced water is usually considered to be a waste but this is now a potential profit stream for the industry [1]. The conventional methods to handle waste stream are reinjection into the well, direct discharge or reuse in case of the thermal loop. Out of these, the most efficient way of handling produced water is to re-inject it into disposal wells. The disposal cost, which includes transportation cost, capital cost and infrastructure maintenance cost, may be as much as $\$ 4.00 / \mathrm{bbl}$. On the other hand, many oil producing regions (West Texas, Middle East and the Central Asian Republics) have scarcity of potable water [1] [2] [3].

With continuously stricter regulations for discharging produced water to the sea, the operators are obliged to look for ways to improve the treatment processes or re-use the water in a beneficial way, for example as a pressure support during oil recovery (produced water re-injection). To improve the knowledge of the underlying phenomena governing separation processes, detailed information of the composition and interfacial properties of produced water is undoubtedly useful and could provide valuable input for better understanding and improving separation models [1]. This review article summarizes knowledge gained about produced water composition and the most common treatment technologies, which are later used to describe the fundamental phenomena occurring during separation. These colloidal interactions, such as coalescence of oil droplets, bubble-droplet attachment or partitioning of components between oil and water, are of crucial importance for the performance of various technologies and are sometimes overlooked in physical considerations of produced water treatment. The last part of the review deals with the experimental methodologies that are available to study these phenomena, provide data for models and support the development of more efficient separation [2] [3].

Some of the options for handling processed water for the oil and gas operator include:

1) Avoid production of water onto the surface-mechanical, by means of screened or chemical gels, which block the water from cracks or fractures or dwelling Water separators re-injecting water into appropriate forms. These solu- 
tions are one of the most elegant but not always practical for wastewater disposal.

2) Manufactured reinjection water-re-injection into the same or other effective formation of the generated water. We move the produced water to the injection site from the producer. Injection therapy can be suitable for minimizing bacteria and fouling and scaling agents. While wastewater is created in this option, waste is found in the underground.

3) Wastewater manufactured-manage the water manufactured for onshore or offshore compliance. In some cases, the water produced may not be suitable for treatment.

These treatment trains do not achieve more restrictive limitations related to the reuse of the effluent (reinjection into extraction wells) or other beneficial uses (e.g., irrigation). Therefore, and to prevent environmental pollution, further polishing processes need to be carried out. Characterization of the PW to determine major constituents is the first step to select the optimum treatment for PW, coupled with environmental factors, economic considerations, and local regulatory framework. This review tries to provide an overview of different treatments that are being applied to polish this type of effluents [4]. These technologies include membranes, physical, biological, thermal or chemical treatments, where the special emphasis has been made on advanced oxidation processes due to the advantages offered by these processes. Commercial treatments, based on the combination, modification and improvement of simpler treatments, were also discussed [4] [5].

4) Reuse in oil and gas operations: process the extracted water for drilling, stimulation, and operations in line with quality requirements.

5) Consumptive uses-in some cases, substantial water treatment is required to ensure consistency in useful uses such as irrigation, regeneration of the rangeland, cattle and animal consumption, and private drinking water or public waters. The main purpose of this study is to a) List the different water management techniques produced and used for oil and gas. b) Investigate each technique separately for the process, request and post-evaluation. c) To comparing and analyze each of these water management strategies' benefits and disadvantages, and d) Evaluating potential development needs to meet waste processing, recycling and recycling standards [6] [7] [8]; With the use of technology in a Western Desert oil and gas field, the most common water management techniques were demonstrated and evaluated in this study. The research area is located in the north of the Western Desert (Figure 1). It covers an area of 18,000 square kilometers, covering 300 and $60 \mathrm{~km}$ in length. It occupies most of the arid belt of Egypt. The Western Desert of Egypt is a vast monoclinic system that dips regionally in the north. In some areas of the monoclinum, the defects, folding and surface gravity differ in different irregularities. In the following sections, the central geological areas are described as the central olive field units, Figure 2 and Figure 3, Bahariya Formation (Late Cenomanian), Abu Roash Formation 


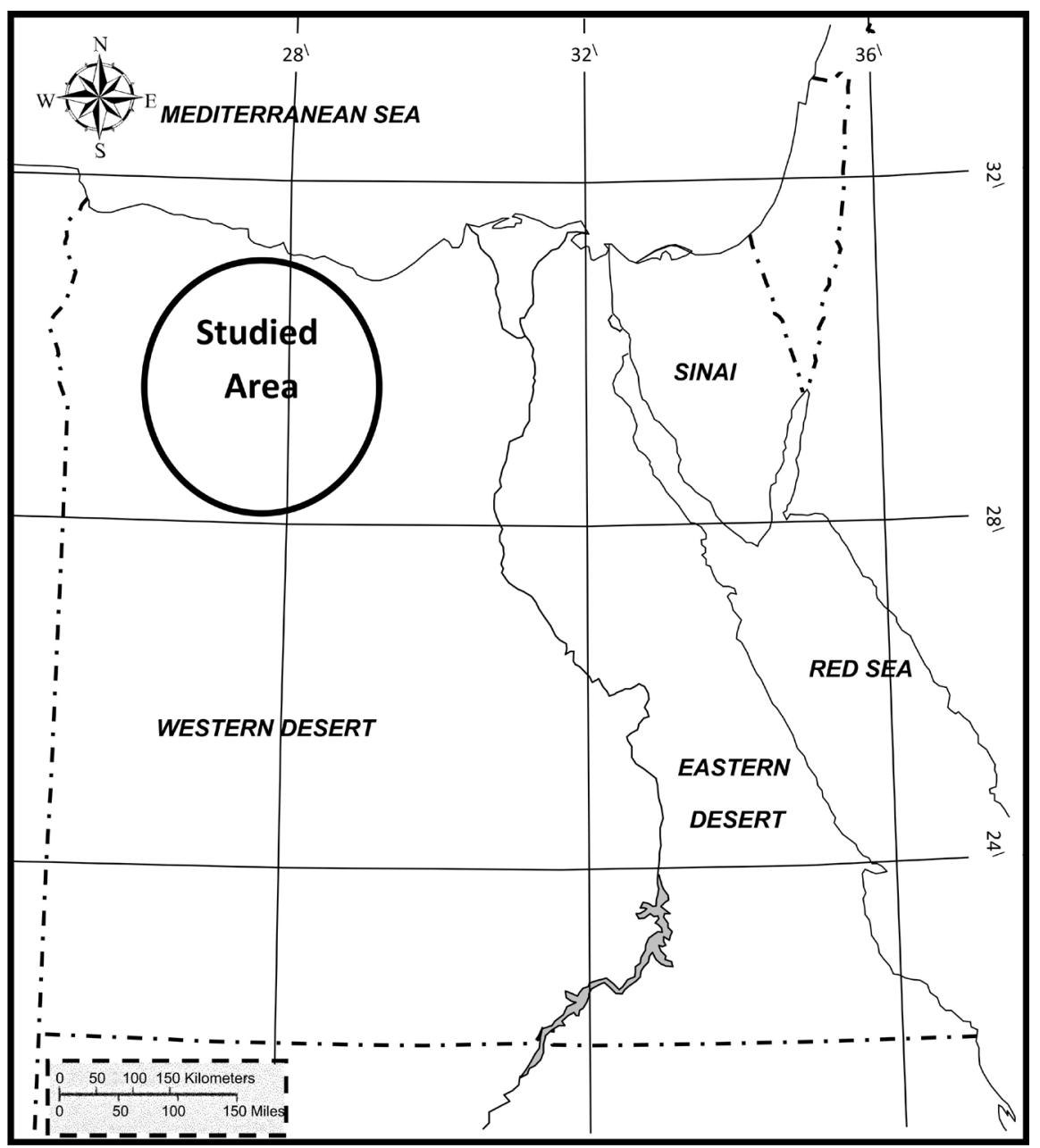

Figure 1. Location map of the study are.

(Turonian-Santonian), Khoman Formation (Maastricht-Campanian), Apollonia Formation (Midel-lower Eocene), Dabaa Formation (Upper Eocene-Oligocene) and Moghra Formation (The Bottom Miocenum) [9]. First, water minimization technologies comprising of three applications in three different wells (Well 1, Well 2 and Well 3) and two techniques for the recycling and reuse of water were selected in these research projects (enhanced for oil recovery, constructed wetland).

Therefore, water requirements management for a town like Bangalore is critical. The city faces an acute shortage of water, which is seen by the widening of the supply-demand gap, Bangalore City's estimated population and water gap by 2051. Water supply will be a major challenge in the coming days, since there is no permanent river. The drawing of water by Cauvery beyond 600 cusecs is also restricted.

\subsection{Produced Water}

It may include water from the formation, water injected into the formation, and any chemicals added during the production and treatment processes (Environmental Protection Agency, 2000) [10]. 
M. A. Kassab et al.

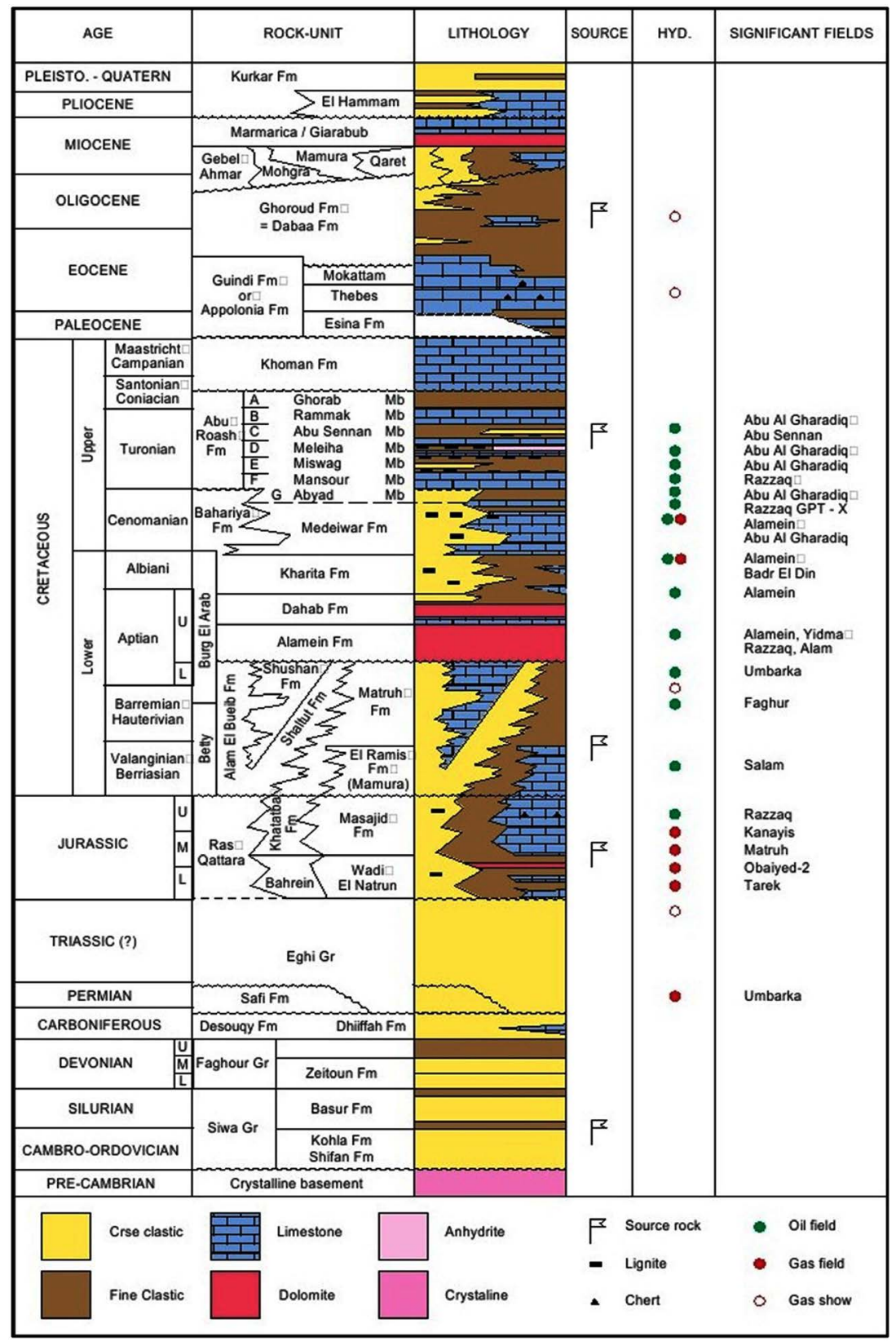

Figure 2. Generalized stratigraphic sequence of the northern part of the western desert (Schlumberger, 1995) [9].

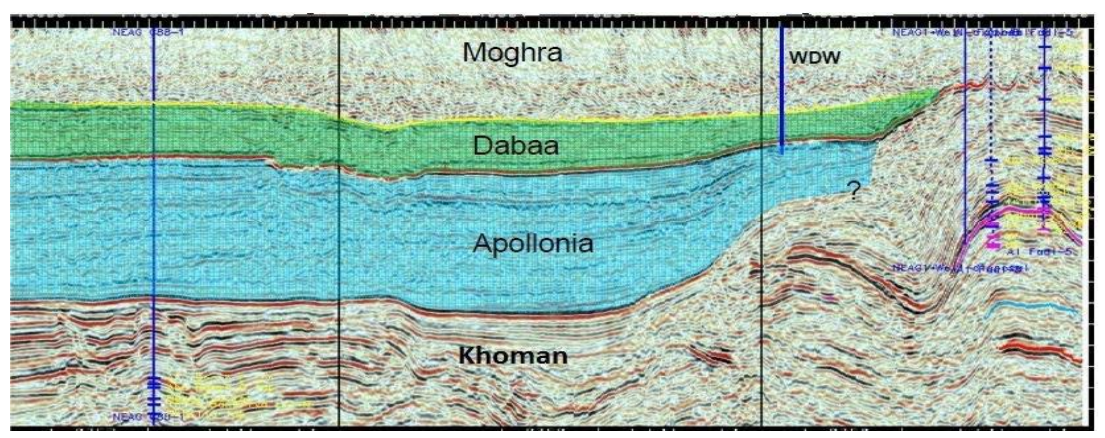

Figure 3. Stratigraphic cross-section of oil field area (Compiled from seismic logs). 
The manufactured water is a considerable volume byproduct or waste stream to discover and develop oil and gas. Eight hundred sixty-seven thousand eight hundred fifty-three oil wells manufactured crude oil worldwide as of December 31,2008 , according to a recent compilation of data, In the United States, about 500,000 are identified. Hundreds of thousands more natural gas wells also contain water provided (Figure 4).

Another way of looking at this is to examine the ratio of water to oil.

- Worldwide estimate-2:1 to 3:1

- U.S. estimate-7:1, because many U.S. fields are mature and past their peak production

- Many older wells in the United States and other countries have ratios > 50:1

Due to the high cost of water supply, economical lives of many pools have been reduced. Such expenses include lifting, service, segregation and disposal. The unwanted water uses the natural movement and leads to a well dropped output. Co-production sources may be obtained either because water is naturally present in reservoirs (e.g. water sources and water for formation) or because water from external sources has been pumped into a reservoir.

\subsection{Water Production Problem}

Water produced is the underground water trapped on the surface along with the processing of oil and gas. The most common environmental issue in oil production involves oilfield affected soil. The oil-producing water contaminates the soil, causing plant deaths and the resulting erosion of the surface of the soils. The soil affected often pollutes surface waters and shallow aquifers.

This paper is aimed at providing an approach to fully characterize polluted soil by produced waters, using various recommended analytical techniques, by analyzing both the water produced and the soil being affected and identifying and testing the key elements that cause soil contamination. The case study for this study was selected for Gialo-59 oilfield (29N, 21E), Libya.

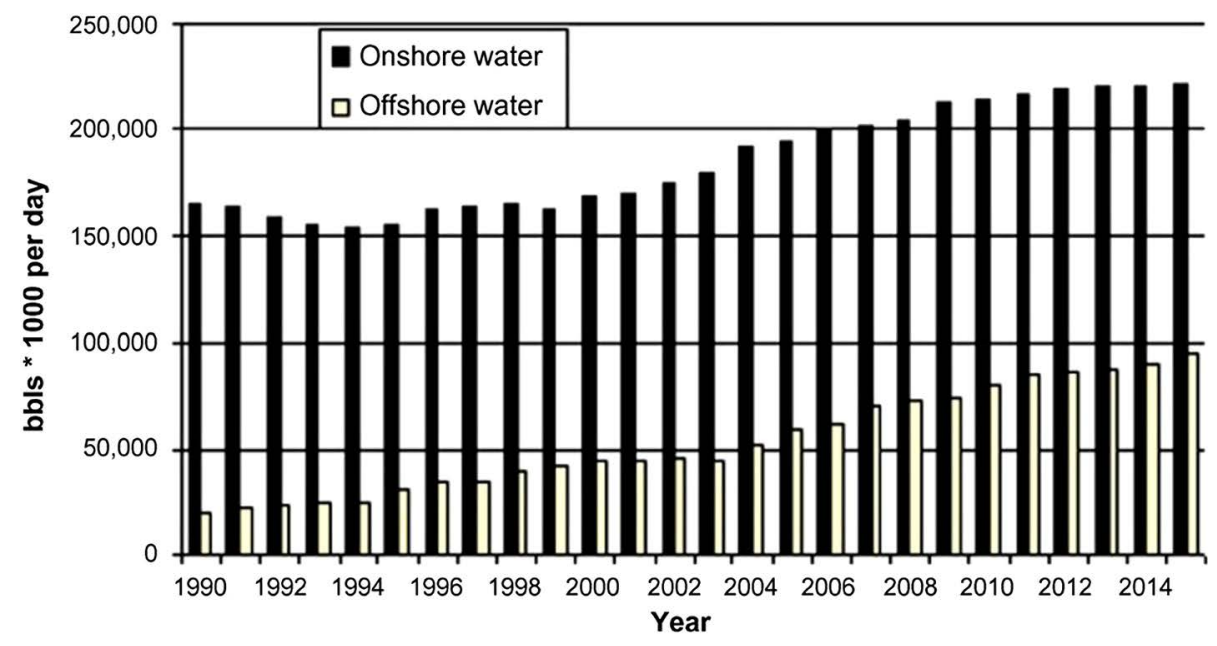

Figure 4. Global onshore and offshore water production (Dal Ferro and Smith, 2007 [3]). 
The field has a long history of oil manufacturing since 1959, where approximately $300,000 \mathrm{bbl}$ of extracted water is dumped into the open fuel. One of the disposal pits collected test samples of polluted soil. During the oil production process samples of the extracted water were collected from different locations and analyzed in Libyan Petroleum Institute's laboratories, in Tripoli, in Libya [11].

In order to prepare for a soil remediation plan we equate the outcomes with local environmental restricting constituents. The findings show that salts and hydrocarbon compounds are the key components (pollutants) that influence the soil. Consequently, an intervention was suggested to eliminate salts and degrade hydrocarbons by soil remediation. Problems with water production are associated with one of the problems: problems with near-wellboards and problems associated with reservoirs. Table 1 summarizes the causes of excess water supply [12].

\subsection{Water Production Diagnostic Problem}

Various technologies can be used to monitor the unwanted output of water. A successful diagnosis of the problem of water production relies on the required range of water control Technologies. Incorrect, inadequate, or incomplete diagnostics are the primary reasons that water control treatments become ineffective [13] [14].

The following subsections include a brief discussion of the most commonly used diagnostic methods: diagnostic plots, logging measurements, and numerical methods.

\subsubsection{Using Plots}

Visual displays help identify the origins of a water issue in the well's lifetime are graphic data plots. Many plot types may be used for the identification and determination of the source of a water issue: Water/oil ratio (WOR) verses time (WOR derivative plots), Oil production versus time, WOR verses cumulative oil, Hall plot-cumulative pressure verses cumulative injection volume, Rate verses time.

Table 1. A summary of the factors that lead to excessive water production.

\begin{tabular}{ll}
\hline Near-wellbore Problems & Reservoir-related Problems \\
\hline Casing leaks & Coning or cresting \\
Channel behind pipe & High permeability streaks \\
Shutting- off perforations & Fracturing job went to water zone \\
Lost circulations while drilling/work over & Watered-out zone \\
Completion into water zone & Channel from injector \\
Temporary chemical isolation & Fractures, fissures, voids, and conduits \\
\hline
\end{tabular}




\subsubsection{Using Logs}

Often logs are used to detect issues in water processing (Table 2). Open hole and output logs are also used for both water saturation and water source detection.

\subsubsection{Using Numerical Method}

Using OK test evaluations that simplify the complex results gained from numerical simulators would be beneficial. It can adequately quantify the effect of treatment by determining the treatment volume, the degree of mobility reduction, and skin damage.

\section{Principles of Produced Water Management}

In the past, handling water produced was the most convenient or cheapest way. Today, many companies accept that water can be a cost or a profit to their companies. Shell has developed a comprehensive water-to-value program to optimize access to water and the cost of water processing processes, and to explore ways to handle more water in existing plants [12].

In most developing countries, existing water management policies contribute to excessively high economic and environmental costs. The scale and implications of these costs have prompted an overall consensus on principles to improve the management of water resources. Indeed, by 2025, more than most developed nations will face a sharp water shortage [15].

It is obvious that better policies on water supplies can have significant impacts. Pricing and tariffs along with legislation have resulted in a range of savings in developed and developing countries of $20 \%$ to $30 \%$ and higher. Improving water management demands that developed countries overcome the significant constraints currently undermining their water resources distribution and productive usage. Experiences in both developing and developed countries have shown, as presented in this paper, that enhanced conservation and relocation policies can have significant benefits. The authorities in question should look for different alternatives such as precipitation, recycling [15] [16].

Table 2. A summary of the diagnostic logs used to identify water problems.

\begin{tabular}{|c|c|c|c|c|c|}
\hline \multirow[b]{2}{*}{ Problem type } & \multicolumn{5}{|c|}{ Proposed Logs } \\
\hline & $\begin{array}{l}\text { Open hole } \\
\text { logs }\end{array}$ & Casing Logs & $\begin{array}{c}\text { Cement } \\
\text { Evaluation logs }\end{array}$ & $\begin{array}{c}\text { Pulsed } \\
\text { Neutron Logs }\end{array}$ & $\begin{array}{c}\text { Production } \\
\text { logs }\end{array}$ \\
\hline Casing leak & & $\sqrt{ }$ & & $\sqrt{ }$ & $\sqrt{ }$ \\
\hline Channel behind pipe & $\sqrt{ }$ & & $\sqrt{ }$ & $\sqrt{ }$ & $\sqrt{ }$ \\
\hline Coning or Cresting & $\sqrt{ }$ & & & & $\sqrt{ }$ \\
\hline High permeability streaks & $\sqrt{ }$ & & & & $\sqrt{ }$ \\
\hline Water out zone & $\sqrt{ }$ & & & & $\sqrt{ }$ \\
\hline Completion near water zone & $\sqrt{ }$ & & & $\sqrt{ }$ & $\sqrt{ }$ \\
\hline Fracture out of zone & & & $\sqrt{ }$ & $\sqrt{ }$ & $\sqrt{ }$ \\
\hline
\end{tabular}


Rainwater harvesting should be made compulsory; wastewater reuse has to be made with dual water supply system for new layouts. As the suburbs in the city are increasing day by day, rainwater harvesting would be able to serve the city for much longer time.

\subsection{Water Minimization Technologies (Table 3 and Table 4)}

Each barrel of additional water generated increases the pump and storage, treatment, and management costs to the surface. The reduction of the volume of water being treated is an excellent way to minimize costs.

Table 3. Mechanical control technologies and applications, advantages and disadvantages (Shell DEP 2005).

\begin{tabular}{|c|c|c|}
\hline Technology & Major Applications & Advantages Disadvantages \\
\hline Bridge Plug & $\begin{array}{l}\text { Shut-off all flow inside casing } \\
\text { from below plug }\end{array}$ & $\begin{array}{l}\text { Inexpensive } \\
\text { High failure rate with poor casing condition } \\
\text { Can't repair channel behind pipe }\end{array}$ \\
\hline $\begin{array}{l}\text { Through Tubing } \\
\text { Bridge Plug }\end{array}$ & $\begin{array}{l}\text { Shut-off all flow inside casing } \\
\text { from below plug }\end{array}$ & $\begin{array}{l}\text { Inexpensive } \\
\text { High failure rate with poor casing condition } \\
\text { Can't repair channel behind pipe } \\
\text { Not applicable in large casing/tubing ID ratio }\end{array}$ \\
\hline $\begin{array}{l}\text { Through tubing } \\
\text { Bridge Plug with } \\
\text { Cement Cap }\end{array}$ & $\begin{array}{l}\text { Shut-off all flow inside casing } \\
\text { from below plug }\end{array}$ & $\begin{array}{l}\text { Inexpensive } \\
\text { High rate of success in gas wells } \\
\text { High failure rate with poor casing condition } \\
\text { Can't repair channel behind pipe } \\
\text { Moderate rate of success in oil wells }\end{array}$ \\
\hline Sand Plug with Cap & $\begin{array}{l}\text { Shut-off all flow inside casing } \\
\text { from below plug }\end{array}$ & $\begin{array}{l}\text { Inexpensive } \\
\text { Flexible design for easy removal (Cap of gel } \\
\text { or particulates) or long life (Cement cap) } \\
\text { Lose sand to voids behind pipe } \\
\text { Can't repair channel behind pipe }\end{array}$ \\
\hline Cement Plug & $\begin{array}{l}\text { Shut-off all flow inside casing } \\
\text { from below plug }\end{array}$ & $\begin{array}{l}\text { Provide semi-permanent plug } \\
\text { Repairs some behind pipe channels } \\
\text { Expensive to remove-Drill out }\end{array}$ \\
\hline Cement Squeeze & $\begin{array}{l}\text { Plugs all exposed perforations } \\
\text { without restricting casing ID }\end{array}$ & $\begin{array}{l}\text { Casing open for recompletion } \\
\text { Mechanically strong to } \mathrm{P} \\
\text { Expensive due to rig operation or to complex } \\
\text { and riskfulrigless operation } \\
\text { Low rate of success in plugging all the } \\
\text { perforations } \\
\text { Fails if casing has large voids behind pipe }\end{array}$ \\
\hline Straddle Packer & $\begin{array}{l}\text { Seal selection of blank pipe } \\
\text { across selected intervals }\end{array}$ & $\begin{array}{l}\text { With good casing, has higher success than } \\
\text { cement squeeze } \\
\text { Mechanically strong long life } \\
\text { Expensive due to rig operation } \\
\text { Reduced ID in respect of casing ID }\end{array}$ \\
\hline Metal Casing Patch & $\begin{array}{l}\text { Place expandable metal tube } \\
\text { covered by resin }\end{array}$ & $\begin{array}{l}\text { Repairs damaged casing or isolates casing } \\
\text { Quite good track record } \\
\text { Expensive due to rig operation }\end{array}$ \\
\hline Flexible Casing Patch & $\begin{array}{l}\text { Place expandable tube of } \\
\text { thermoset resin that cures after } \\
\text { placement }\end{array}$ & $\begin{array}{l}\text { Runs through tubing on electric wireline } \\
\text { Repairs damaged casing or tubing with } \\
\text { minimal reduction of diameter } \\
\text { New-Little history of success rate or lifetime }\end{array}$ \\
\hline
\end{tabular}


Table 4. A summary of preformed gel systems (Seright, 1996) [14].

\begin{tabular}{|c|c|c|c|c|}
\hline $\mathrm{Me}$ & Developer & Particle Size & & Applications \\
\hline BrightWater $^{\circledR}$ & Chevron, BP and Nalco & Sub-Micro $(<1 \mu \mathrm{m})$ & $60^{+}$ & injectors \\
\hline Microgel & IFP & $\operatorname{Micro}(1-10 \mu \mathrm{m})$ & $10^{+}$ & producer \\
\hline PPG & $\begin{array}{c}\text { Petro China } \\
\text { MS \& } \mathrm{T} \text {, and Halliburton }\end{array}$ & $\begin{array}{c}\text { Millimeter } \\
(10 \mu \mathrm{m} \text { to millimeters })\end{array}$ & & $\begin{array}{c}5000+ \\
\text { Injectors in China }\end{array}$ \\
\hline pH Sensitive polymer & UT & Micro & & Not Reported \\
\hline
\end{tabular}

\subsubsection{Reduce the Volume of Water Entering the Well}

In order to prevent water from entering the well, two primary technologies can be used: mechanical blocking equipment and chemical products which can shut down channels or fracture in the formation (Figures 5-7), thereby preventing water from entering the well.

\subsubsection{Minimize the Volume of Water Reaching the Surface}

Separation of water can be performed inside the wellbore using downhole oil/water or gas/water separators or through dual-completion wells. Although a full DOWS system includes many components, the two primary components are an oil-water separator and at least one downhole injection pump. Two types of separators: hydrocyclone and gravity separators (Figure 8), and three types of pumps: electric submersible pumps (ESP), progressing cavity pumps, and beam pumps have been employed. The individual components of DOWS technology have been proven to work in the field. The challenge is to make separators and pumps work together in the confined space of a 7 " or smaller casing in a bottom hole environment.

Downhole separation technology allows oil, gas and water to be separated downhole and produced water to be disposed underground. It can reduce water production and save energy from lifting produced water to surface.

Downhole separation technology is theoretically feasible, but technically immature. Based on the review, only $60 \%$ of the worldwide applications were successful. The industrial adoption of downhole separation technology has been stagnant due to this low reliability. As a result, most service companies have abandoned downhole separation tools.

The most recognized problem from the previous applications is the injectivity decline during injection of separated water. The impurities in the injected water clogged the formation and caused the whole process to fail. In addition, separators and pumps have different characteristics under different downhole environments. The separation processes under various conditions and related fluid properties are not well understood. Lastly, downhole separation technology makes the well structure much more complicated than conventional completions, which naturally introduces more mechanical failures from the pumps, motors, or separators. All in all, most failures can be attributed to the lack of 


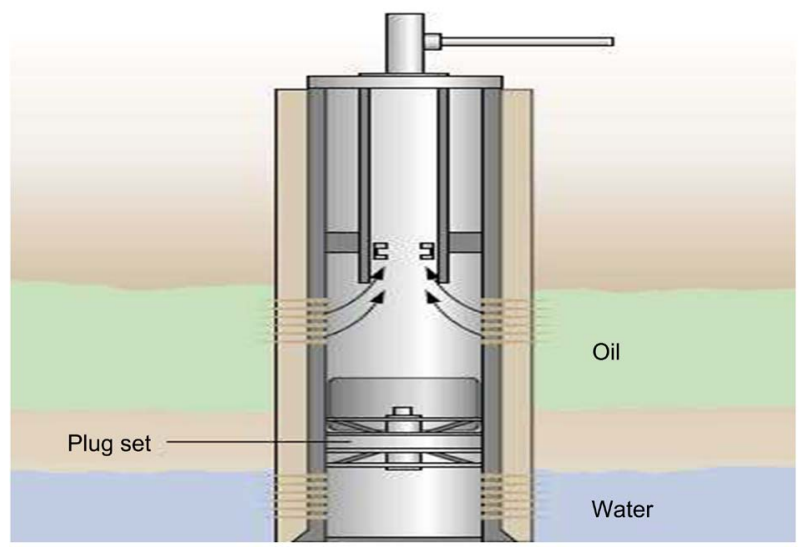

Figure 5. Mechanical plug back tool (Bailey et al. 2000).
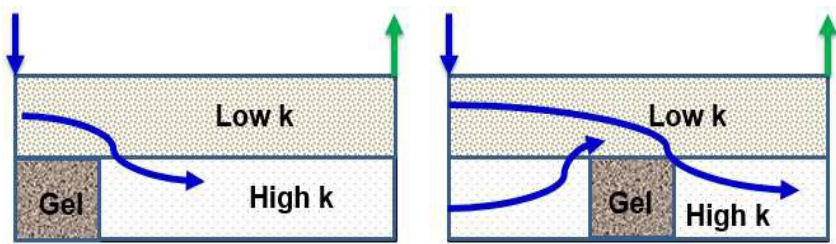

Figure 6. Near wellbore vs. in-depth treatment (Viel 2007) [17].

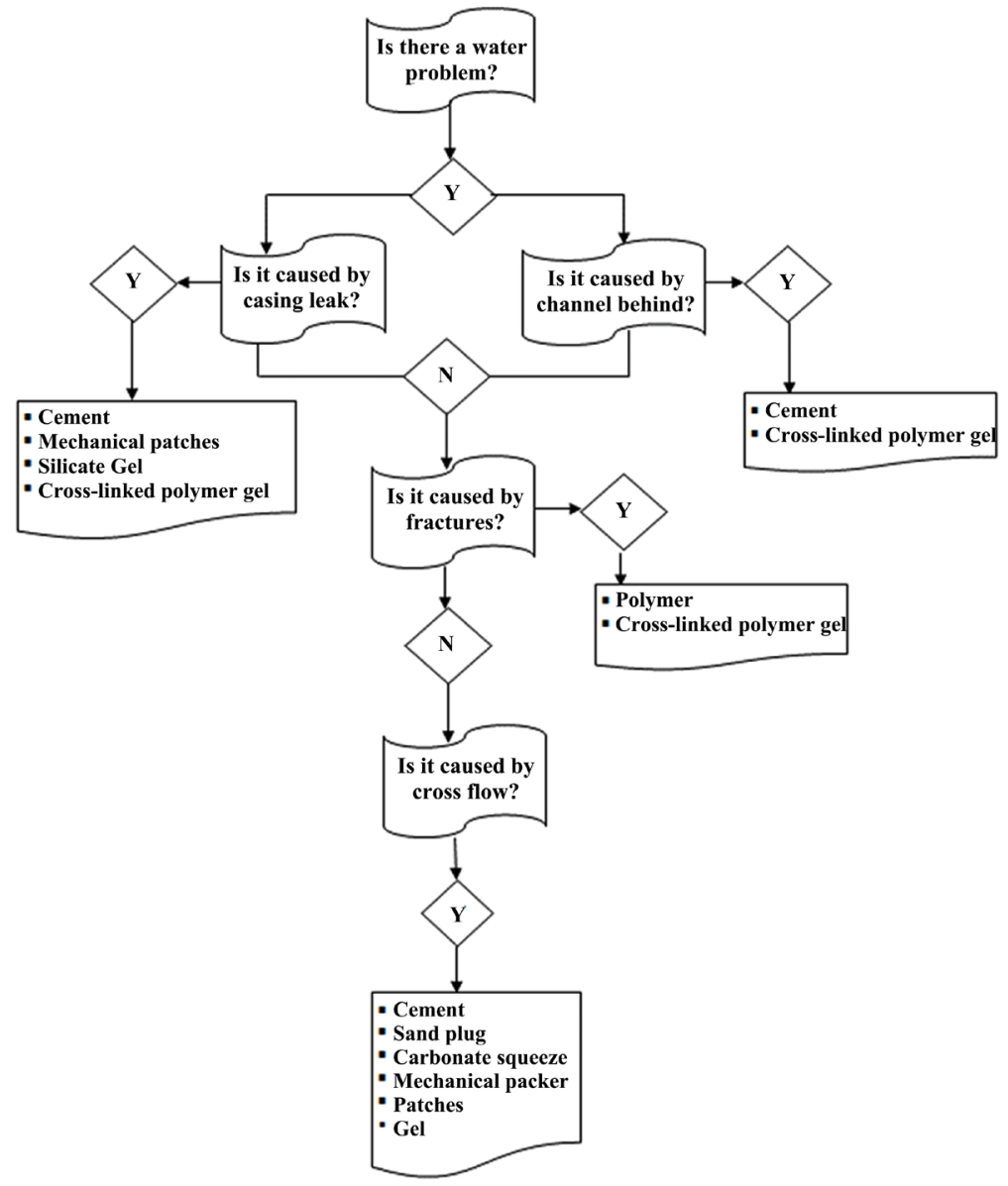

Figure 7. Water management loop. 


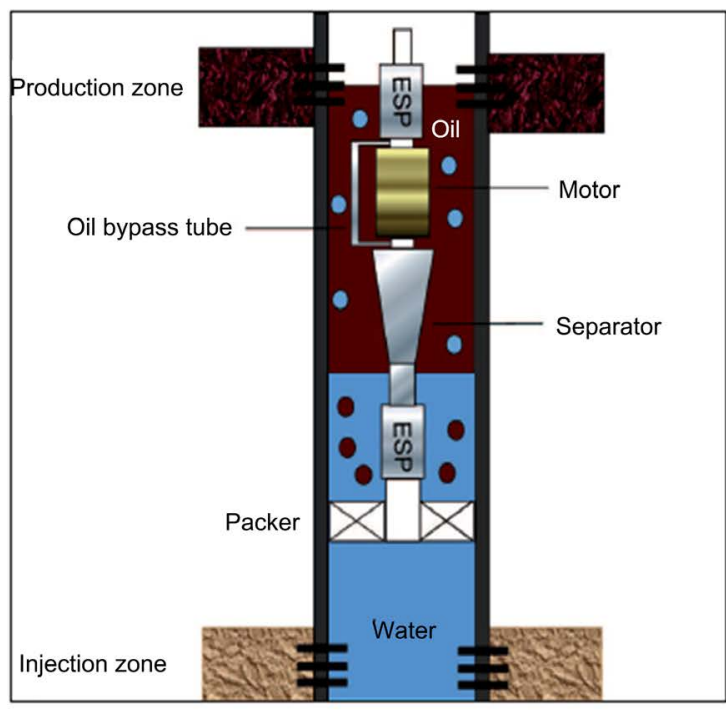

(A)

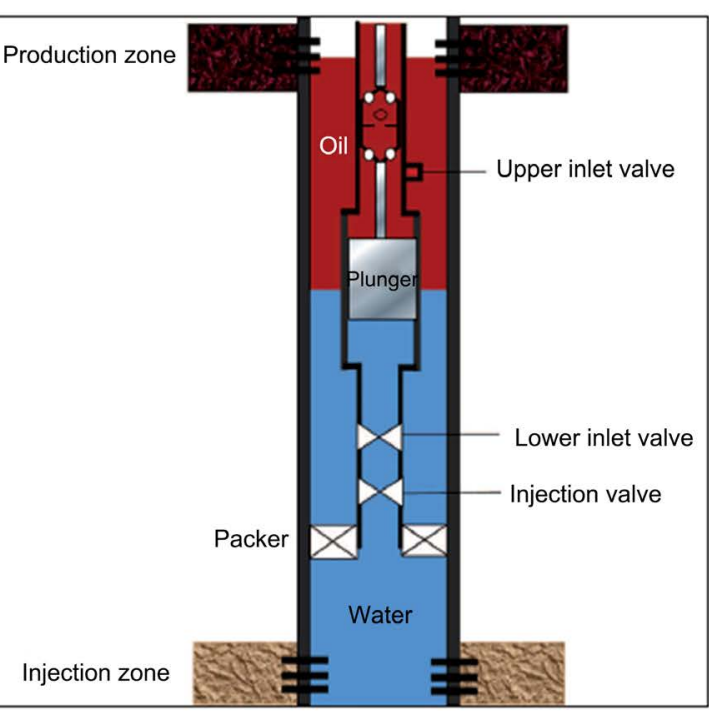

(b)

Figure 8. (A) Hydrocyclone separator type (B) gravity separator type (Veil et al. 1999) [16].

thorough understanding of the separation and injection processes. Downhole separation technology has great potential in gas well dewatering and deep water reservoir development.

\subsection{Recycle and Reuse Technologies}

In the rapidly developing shale gas industry, managing produced water is a major challenge for maintaining the profitability of shale gas extraction while protecting public health and the environment. The large volume of produced water is also viewed as potential source of water for various usages such as irrigation, potable water, and industrial process water. However, the complex mixture of pollutants presents the challenges for achieving treatment steps that both cost effective and high efficiency [15] [16] [17] [18]. Therefore, numerous efforts were made to develop more economical and advanced treatment technologies to meet various end-use requirements. There're several ways in which produced water can be recycled or reused. Some of the processes can use the water regardless of its chemical constituents. We review the current state of practice for produced water management across the United States and discuss the interrelated regulatory, infrastructure, and economic drivers for produced water reuse. Within this framework, we examine the Marcellus shale play, a region in the eastern United States where produced water is currently reused without desalination. In the Marcellus region, and in other shale plays worldwide with similar constraints, contraction of current reuse opportunities within the shale gas industry and growing restrictions on produced water disposal will provide strong incentives for produced water desalination for reuse outside the industry. The most challenging scenarios for the selection of desalination for reuse over other management strategies will be those involving high-salinity produced water, which must be desalinated with thermal separation processes. We explore desa- 
lination technologies for treatment of high-salinity shale gas produced water, and we critically review mechanical vapor compression (MVC), membrane distillation (MD), and forward osmosis (FO) as the technologies best suited for desalination of high-salinity produced water for reuse outside the shale gas industry. The advantages and challenges of applying MVC, MD, and FO technologies to produced water desalination are discussed, and directions for future research and development are identified. We find that desalination for reuse of produced water is technically feasible and can be economically relevant. However, because produced water management is primarily an economic decision, expanding desalination for reuse is dependent on process and material improvements to reduce capital and operating costs.

\subsubsection{Injection for Enhanced Recovery}

Co-produced water re-injection is a mature recovery technique for oil fields (water injection system is shown in Figure 9). Co-produced water that is not re-injected is the largest wastage stream in the oil industry. Handling, treatment and management (especially re-injection back into the reservoir) is an expensive operation. PWRI is a secondary oil recovery method with a small recovery factor in the range of $15 \%-25 \%$ and contributes to many surface and subsurface issues, e.g., scaling and reservoir plugging, resulting in the decline of water injectivity, and thus lower oil recovery. This reduction, of course, impinges significantly on the revenue stream of major oil corporations. However, low-salinity (LowSal) water injection is an emerging method that boosts oil recovery by reducing the downsides of produced water re-injection. Using forward osmosis to produce low-salinity water for injection is a novel idea, in which the co-produced water will be the draw solution. In this concept, low-salinity water from water wells (brackish water) is used as the feed to dilute the co-produced water. The diluted co-produced water will then be re-injected as LowSal water [2]. The

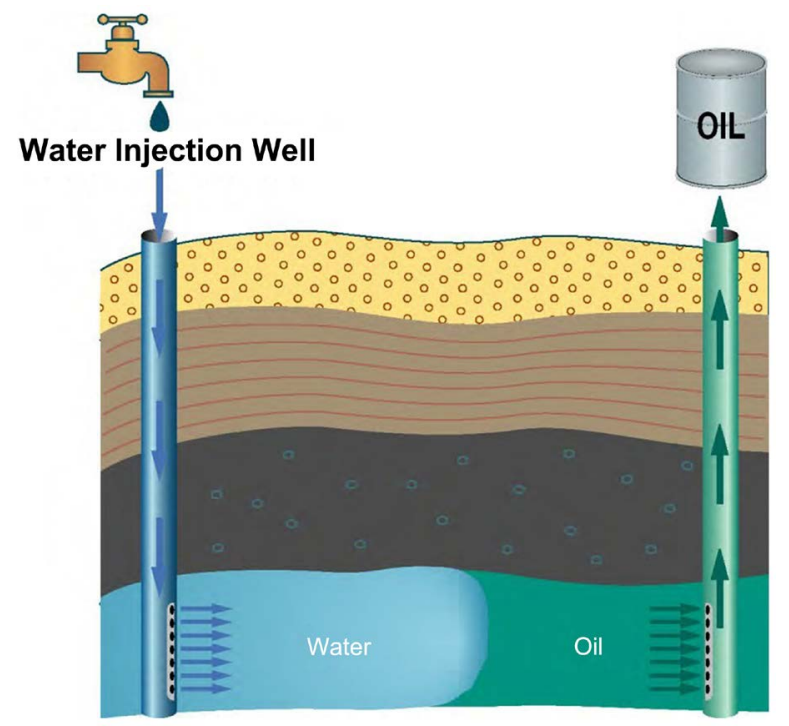

Figure 9. Water injection system. 
obviously cheaper alternative of direct dilution of the co-produced water with the brackish water might not produce water compatible with the oil reservoir in both ionic composition and strength. Data have been collected from different oil fields with various co-produced water and formation characteristics. Different co-produced water treatments were observed in each oil field due to differences in co-produced water chemistry. The water sample for analysis was taken at the skim tanks prior to the water injection stage. A theoretical resistance-in-series model for the forward osmosis stage is presented, which has been adapted from the literature, which incorporates the mass transfer equations, in which the boundary layer and thin-film theory for the membrane intrinsic layers are integrated. An improved shell mass transfer correlation is introduced in addition to the incorporation of a modified reflection coefficient into the resistance-in-series model. The collected data were then incorporated into the theoretical model to calculate and evaluate the forward osmosis performance and, in turn, the water chemistry before re-injection. A forward osmosis rig has been erected to use the latest hollow fiber membrane supplied by the Toyobo Company (Japan). Water and solute flux were measured to validate the model estimations. The model estimated results were at $95 \%$ confidence to the measured values. Analytical investigations (ion analysis) for the membrane filtrate at various flow rates and applied pressures were performed to determine the forward osmosis filtrate ion composition. The FO filtrate compositions were then simulated using ScaleChem studio software from OLI for scaling tendency. The software predicted a remarkable reduction in the scaling tendency in the injection water infrastructure (including the oil reservoir) and by more than $50 \%$ compared to conventional co-produced water re-injection. Parallel to the ScaleChem predictions, the FO filtrate water was experimentally investigated for scaling using the Differential Scaling Loop rig, in a third-party lab. The DSL results are in good agreement with the ScaleChem predictions. The experimental scaling tendency results show that the injection of forward osmosis filtrate has the minimum occurrence of scaling both in the surface and subsurface. This new concept to produce LowSal produced water re-injection has the potential to improve oil recovery by minimizing the oil reservoir plugging due to scaling. The most widely used approach to onshore water management. The majority of the water generated (71 percent) is pumped into the reservoir and drives oil hydraulically to the source [3] [4].

To avoid the plugging of the formation pores or equipment damage, it is necessary to ensure that the injected water is consistent with the water obtained by the formation [19].

\subsubsection{Wet Land (Figure 10)}

Constructed wetlands are alternative processes for waste water treatment that embraces the same concept as natural processes for treating water. Microorganisms naturally available in water, on the rocks, in soil and on the stems and roots of plants in wetlands feed on nutrients removing pollutants from water [13] [14] [17]. 

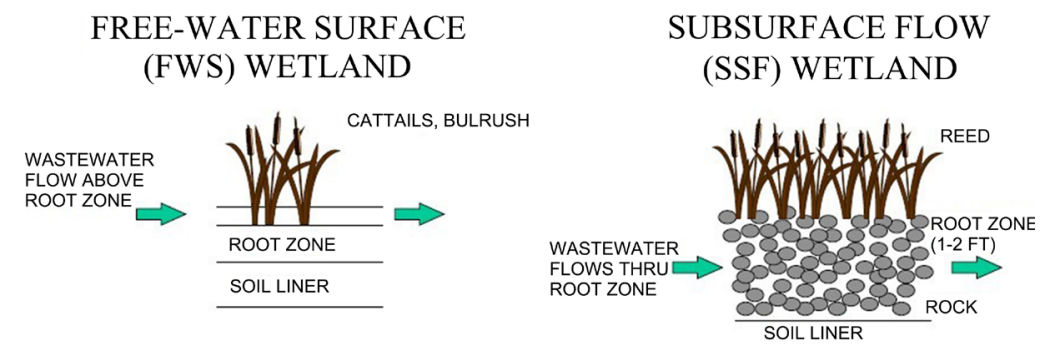

Figure 10. Types of wetlands (Veil, 2007) [17].

\subsection{Disposal Technologies}

At least four methods can be used to dispose of produced water. One common disposal method (discharge) typically requires treatment before the produced water can be released. A second method (injection) may or may not require treatment. The other two methods (evaporation and commercial disposal) can directly dispose of produced water without undertaking any treatment.

\section{Results and Discussion}

\subsection{Magnitude of the Problem}

The daily production oil is 16,479 bopd, and the daily produced water is 31,483 bwpd, (Table 5) within taken in consideration the daily condensate $5828 \mathrm{bcpd}$, the cumulative production will be $22,307 \mathrm{bpd}$, so for every oil or condensate barrel produced from the wells about 1.5 barrel of water will be produced which is resulted in high cost of water management of this quantity of water.

\subsection{Applications of Water Management Techniques}

A. Water Minimization Techniques on Well 1

Well1 is subjected to mechanical shut-off technique (Figure 11) by isolating the water bearing zone via thorough tubing bridge plug and $5 \mathrm{~m}$ of cement dumped above it, the water cut decreased from $100 \%$ to $4 \%$, also the condensate production increase from 0 to $400 \mathrm{bcpd}$.

B. Water Minimization Techniques on Well 2

Well 2 is subjected to chemical shut-off technique (Figure 12) using polymer called Brightwater, initially the well produced $4000-4500$ bpd gross oil at water cut of $25 \%-40 \%$. The increase in net oil was initially almost 2500 bopd that declined to 1000 bopd during one year of production

C. Water Minimization Techniques on Well 3

Well 3 is subjected to downhole separator (DOWS) Hydrocyclone type (Table 6) installed immediately above water bearing zone.

D. Recycling and Reusing Technologies Application

Injection for Enhanced Recovery

By reinject the quantity of water equal to $4.19 \mathrm{MMbbl}$.via two injection wells during two years as illustrated in Figure 13. This reflects in the excess of cumulative oil production from 0.77 MMbbl. to 2.2 $\mathrm{MMbbl}$. during that period and the excess of oil is $1.43 \mathrm{MMbbl}$. 
Table 5. Daily Production figure of the field.

\begin{tabular}{ccc}
\hline Oil & Condensate & Water \\
\hline $16,479 \mathrm{bbl}$. & $5828 \mathrm{bbl}$. & $31,483 \mathrm{bbl}$. \\
\hline
\end{tabular}

Table 6. Production volumes for DOWS trials in central Alberta reef trends.

\begin{tabular}{cccccc}
\hline & & \multicolumn{3}{c}{ Production (bbl/day) to surface } \\
\cline { 3 - 6 } Operator and Well & Type of DOWS & \multicolumn{2}{c}{ Pre-DOWS } & \multicolumn{2}{c}{ Post-DOWS } \\
\cline { 3 - 6 } & & Oil & Water & Oil & Water \\
\hline \multirow{2}{*}{ Well\#3 } & Hydrocyclone & 44 & 1038 & 100 & 217 \\
\hline
\end{tabular}

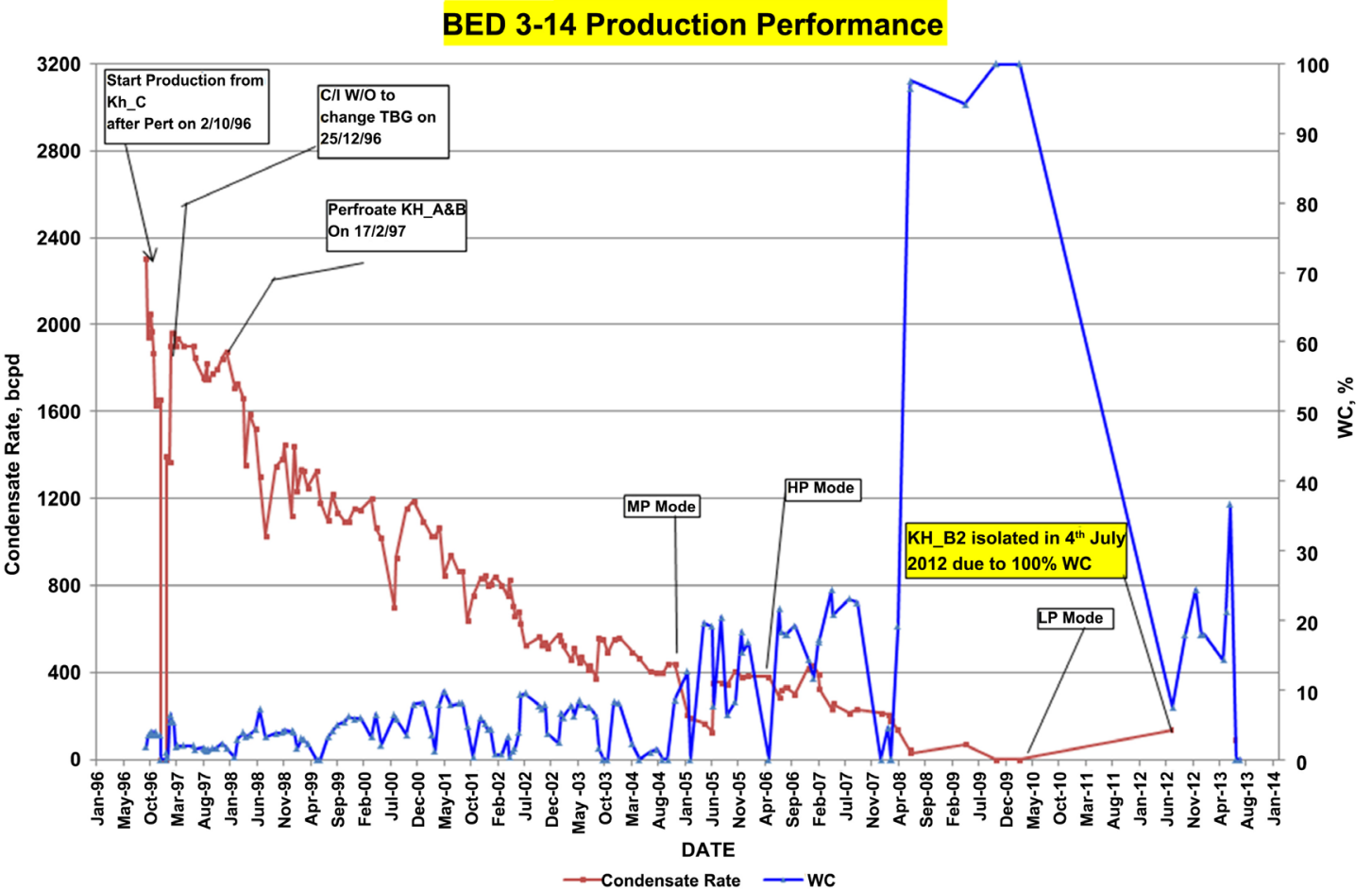

Figure 11. Production performance of Well 1.

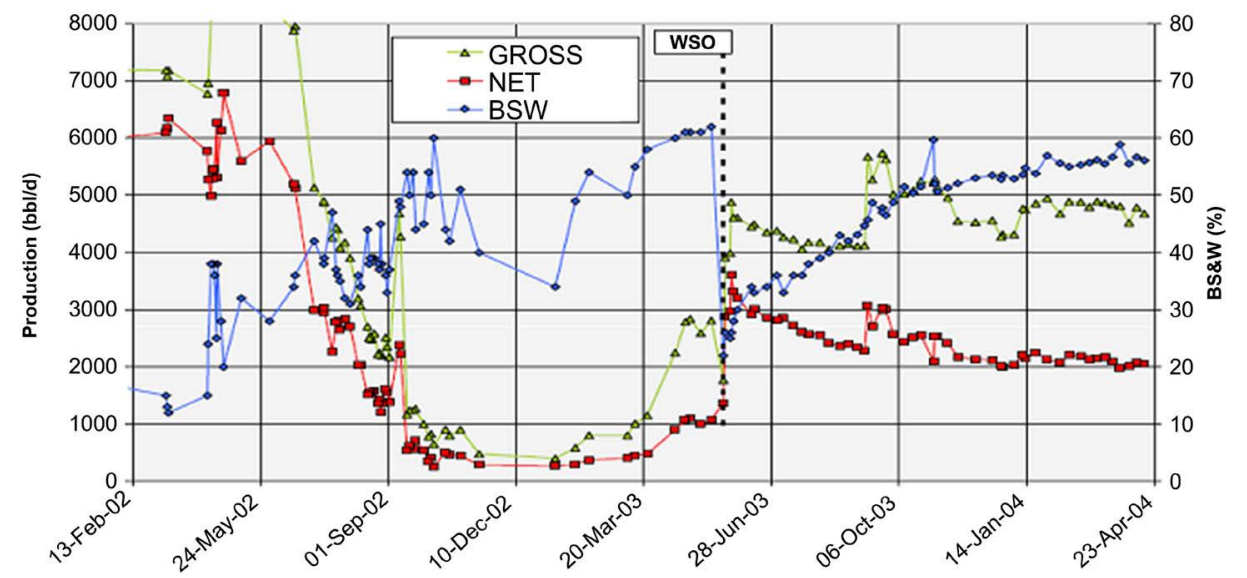

Figure 12. Production performance of Well 2. 


\section{Production Performance}

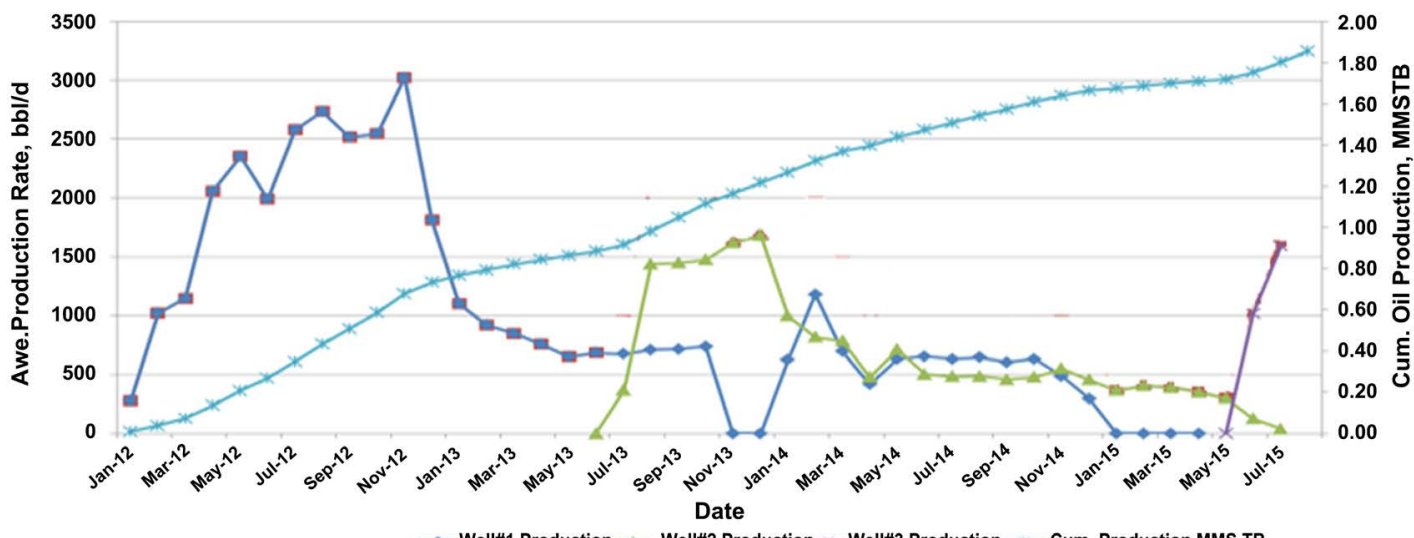

Figure 13. Production performance of injection.

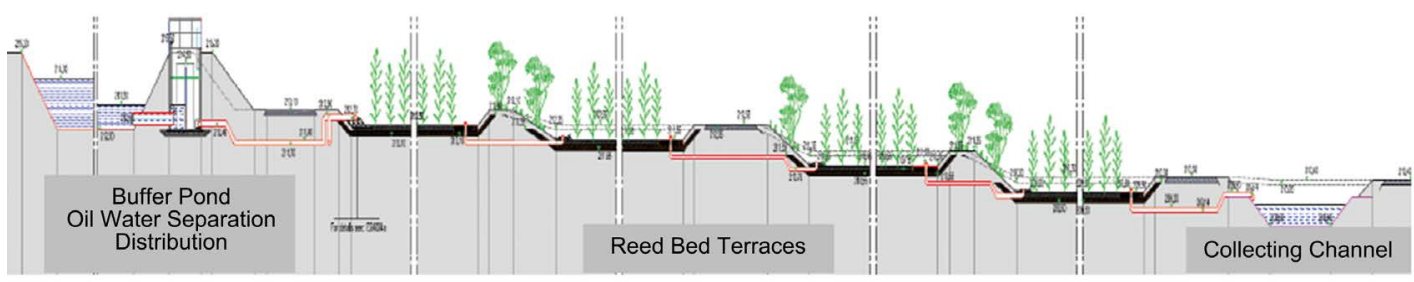

Figure 14. Nimr oil field water treatment plant cross section (Myers, 2000) [13].

\section{E. Constructing Wetland}

The Nimr water treatment plant project (Figure 14) is located in the south of Muscat in Oman. This water treatment plant came online in late 2010 and has been treating water since 18th December December 18 2010. The Nimr oilfield requires $250,000 \mathrm{~m} / \mathrm{d}$ of water to be managed to keep oil production going. The composition of the produced water from the Nimr oilfield is brackish, with total dissolved solids ranging between $7000 \mathrm{mg} / \mathrm{l}$ and $8000 \mathrm{mg} / \mathrm{l}$. The oil in the water is higher than $400 \mathrm{mg} / \mathrm{l}$ in average [3] [16].

\section{Summary and Conclusion}

- Management of the vast volume of produced water generated by the industry (estimated at 77 billion barrels per year all over the world in 2007) can be expensive and challenging.

- Many technologies are developed to manage produced water in terms of three-tiers (i.e., minimization, recycle/reuse, and disposal). It is very important to understand the water production mechanism to recommend the most adequate solution.

- Mechanical technique could be effective in case of good configuration of the well and in case of barrier or separation between water zone and non-water zone. The mechanical technique is effective only on the near well bore problems and don't provide long term solution for reservoir problem 4. From the feasibility study, mechanical shut-off technique is the cheapest minimization 
technique and the pay-out time is low comparing with chemical shut-off technique.

- At most onshore wells, produced water is reinjected for enhancing recovery, this technique is commonly used and it's the first choice. It's highly recommended to treat the produced water before injection as it can cause formation damage or blockage.

- Deep hydrogeological and petrophysical studies are must before choosing the disposing formation, otherwise, it can cause formations damage or aquifer contamination.

- Downhole separator is very attractive and has a great potential to save money and reduce the environmental impacts of managing produced water at the surface 8. Wetland is a best practice solution for produced water treatment if the water composition is suitable for biological treatment. Wetland couldn't use when produced water has a total dissolved salt greater than $7000 \mathrm{ppm}$ or when it's contained toxic material. The capital and operation cost of a wetland plant is low compared to the capital and operation cost of ordinary water treatment plants. The wetland plant's capital and operation costs are low compared with ordinary water treatment plants' capital and operation costs.

- Future produced water management technologies should focus on reduced treatment costs and extracting the secondary value from water (extraction of minerals, power, or other factors). Defining the wellbore water influx mechanism to select the appreciate type of water shut-off treatments.

\section{Conflicts of Interest}

The authors declare no conflicts of interest regarding the publication of this paper.

\section{References}

[1] Ali, S.A., Henry, L.R., Darlington, J.W. and Occhipinti, J. (1999) Novel Filtration Process Removes Dissolved Organics from Produced Water and Meets Federal Oil and Grease Guidelines. The 9 th Annual Produced Water Seminar, Houston, Texas, 21-22 January 1999, 21-22.

[2] API (2000) Overview of Exploration and Production Waste Volumes and Waste Management Practices in the United States. American Petroleum Institute, May 2000.

[3] Dal, F.B. and Smith, M. (2007) Global Onshore and Offshore Water Production.

[4] Bailey, B., Crabtree, M., Tyrie, J., Elphick, J., kuchuk, F., Romano, C. and Roodhart, L. (2000) Water Control. Oilfield Review, 12, 30-51.

[5] Borealis Geopower (2010) Co-Production: Geothermal Energy from Oilfield Waste Water Borealis Geopower.

[6] Clark, C.E. and Veil, J.A. (2009) Produced Water Volumes and Management Practices in the United States (ANL/EVS/R-09/1) U.S. Department of Energy-National Energy Technology Laboratory, September 2009.

[7] Dusseault, M.B. (2001) CHOPS: Cold Heavy Oil Production with Sand in the Cana- 
dian Heavy Oil Industry. Alberta Department of Energy, 301.

[8] Dusseault, M.B. (2008) Reservoir Enhancements and Production Technology Sequencing. World Heavy Oil Congress 2008, Edmonton, Alberta, Canada, 10-12.

[9] Environmental Protection Agency (2000) Profile of the Oil and Gas Extraction Industry. EPA/310-R-00-004.

[10] Imqam, A., Bai, B., Al-Ramadan, M., Wei, M., Delshad, M. and Sepehrnoori, K. (2014) Preformed Particle Gel Extrusion through Open Conduits during Conformance Control Treatments. SPE Improved Oil Recovery Symposium, Tulsa, Oklahoma, USA, 12-16 April 2014, Article No. SPE-169107-PA.

https://doi.org/10.2118/169107-MS

[11] Khatib, Z. and Verbeek P. (2003) Water to Value-Produced Water Management for Sustainable Field Development of Mature and Green Fields. Journal of Petroleum Technology, 55, 26-28. https://doi.org/10.2118/0103-0026-JPT

[12] Myers, J.E. (2000) Constructed Wetlands Overview for the Petroleum Industry., SPE International Conference on Health, Safety and the Environment in Oil and Gas Exploration and Production, Stavanger, Norway, 26-28 June 2000, Article No. SPE-61181-MS. https://doi.org/10.2118/61181-MS

[13] Seright, R.S., Lane, R.H. and Sydansk, R.D. (2001) A Strategy for Attacking Excess Water Production. SPE Permian Basin Oil and Gas Recovery Conference, Midland, Texas, 15-17 May 2001, Article No. SPE-70067-MS. https://doi.org/10.2118/70067-MS

[14] Veil, J.A., Puder, M.G., Elcock, D. and Redweik, R.J. (2004) A White Paper Describing Produced Water from Production of Crude Oil, Natural Gas, and Coal Bed Methane. U.S. Department of Energy National Energy Technology Laboratory, 79. https://doi.org/10.2172/821666

[15] Veil, J.A., Langhus, B.G. and Belieu, S. (1999) Feasibility Evaluation of Downhole Oil/Water Separation (DOWS) Technology. U.S. Department of Energy, Office of Fossil Energy, National Petroleum Technology Office, by Argonne National Laboratory, CH2M-Hill, and Nebraska Oil and Gas Conservation Commission.

[16] Veil, J.A. (2007) Research to Improve Water-Use Efficiency and Conservation: Technologies and Practice. Testimony before the United States House of Representatives Committee on Science and Technology, Subcommittee on Energy and Environment, Washington DC, 30 October 2007.

[17] Veil, J.A. and Quinn, J.J. (2008) Water Issues Associated with Heavy Oil Production (ANL/EVS/R-08/4). U.S. Department of Energy-National Energy Technology Laboratory, November 2008, 64.

[18] Lee, R., Seright, R., Hightower, M., Sattler, A., Cather, M., McPherson, B., Wrotenbery, L., Martin, D. and Whitworth, M. (2002) Strategies for Produced Water Handling in New Mexico. 2002 Ground Water Protection Council Produced Water Conference, Colorado Springs, Colorado, 16-17 October 2002.

[19] Schlumberger (1995) Well Evaluation Conference of Egypt. Technical Editing Services, Ltd., Chester, 87. 